\title{
Development and characterization of synthetic amphiploid (AABB) between Oryza sativa and Oryza punctata
}

\author{
Aiyun Wang $\cdot$ Xianhua Zhang $\cdot$ Chunhua Yang • \\ Zhaojian Song $\cdot$ Chaoqun Du $\cdot$ Dongling Chen • \\ Yuchi He $\cdot$ Detian Cai
}

Received: 14 May 2012/Accepted: 20 October 2012/Published online: 31 October 2012

(C) The Author(s) 2012. This article is published with open access at Springerlink.com

\begin{abstract}
Oryza punctata, a wild relative of cultivated rice, belongs to the $\mathrm{BB}$ genome of Oryza. Interspecific hybrids (CW008, AB) between Oryza sativa $(2 n=24 \mathrm{AA})$ and $O$. punctata $(2 n=24 \mathrm{BB})$ were obtained using embryo rescue technique. Synthetic allopolyploid (DCW008, AABB) were produced through chromosome doubling by colchicine. Hybrids overcame many wild traits except the shattering and awn. The synthetic amphiploid plants showed obvious superiority in growth and production. Interspecific hybrids CW008 were completely infertile but
\end{abstract}

Xianhua Zhang and Aiyun Wang contributed equally to this study. All research had been completed in Hubei University, China.

A. Wang $\cdot$ X. Zhang $\cdot$ Z. Song $\cdot$ D. Chen $\cdot$

Y. He $\cdot$ D. Cai $(\bowtie)$

Faculty of Life Science, Hubei University,

Wuhan 430062, People's Republic of China

e-mail: caidt8866@yahoo.com.cn

Present Address:

A. Wang

Faculty of Life Science, Ludong University, Yantai

264025, Shandong, People's Republic of China

C. Yang

University for Science and Technology Beijing, Beijing

102206, People's Republic of China

C. Du

Forestry Science Research Academy of Hubei Province, Wuhan 430075, People's Republic of China
DCW008 had better seed set after selfing. Genomic in situ hybridization investigations were performed on DCW008. The result indicated that the A genome was closed to the B genome and translocations occurred between some chromosomes of cultivated and wild rice. Meiosis was nearly normal in the amphiploid hybrid but was disrupted in the diploid hybrid, which resulted in different fertility of them.

Keywords Oryza punctata - Amphiploid · Distant hybridization · GISH · Introgression

\section{Introduction}

Rice is one of the world's three major food crops, providing a major source of food for more than $60 \%$ of the world population. Faced on the pressure of a growing world population, the decrease in available arable land and the increasing quality of life, it has become important to increase rice yield and quality. However, the genetic resources of cultivated rice 
have become relatively limited and the task of super rice breeding has become extremely difficult. Therefore, wild rice with rich genetic resources has become very important in rice breeding (He 1998; Deng et al. 2006; Zhu et al. 2008). The wild species are sources of useful genes for resistance to major disease and insects and for tolerance to abiotic stresses (Multani et al. 1994). Some useful genes have successfully been transferred from wild rice into cultivated rice, such as the gene for resistance to the grassy stunt virus from Oryza nivara (Khush 1977), cytoplasmic male sterility from $O$. sativa $f$. spontanea (Lin and Yuan 1980), bacterial blight resistance gene Xa21 from Oryza longistaminata (Khush et al. 1990), rice blast resistance gene pi9 from Oryza minuta (Amante-Bordeos et al. 1992). The genus Oryza consists of 22 wild species which have been certified, including AA-genome and non-AA-genome species. Cultivated rice and AA-genome wild species can be easily crossed. So, useful genes from the AAgenome wild species can be transferred into rice through conventional hybridization and backcrossing procedures. But hybridization between cultivated rice and non-AA-genome wild species are very difficult. The serious interspecific reproductive barriers make it difficult to transfer useful genes from the non-AAgenome wild species to cultivated rice (Zhong et al. 2000). Although with the development of the tissue culture technique, some interspecific hybrids have been developed and some useful genes from nonAA-genome wild species have been transferred into cultivated rice, the efficiency is still low. Polyploid rice with more genome has good plasticity. So, they can play a bridge role in the distant hybridization and promote the utilization of useful genes from wild species (Huang et al. 2001; Carvalho et al. 2005). To date, some artificial allopolyploidizations of Oryza have been created. A part of them had seed set after selfing (Wang et al. 2005). In this study, interspecific hybrids (AB) between $O$. sativa and $O$. punctata (BB genome) were obtained through embryo rescue. Amphiploid intergenomic hybrids (AABB) were produced through chromosome doubling by colchicine. The genomic components of the hybrid were verified by using GISH. A comparison and analysis between the diploid and synthetic amphiploid were undertaken for the main agronomic traits, pollen fertility and meiosis behavior.

\section{Materials and methods}

Plant materials

The cultivated rice Sgdts96, HN2026, Nipponbare (O. sativa, AA, $2 n=2 x=24$ ) were japonica rice lines stored at the Polyploid Genetics Lab of Hubei University, Wuhan, China. Wild rice O. punctata, (BB, $2 n=2 x=24$, IRRI Number: 105980) was kindly provided by the International Rice Research Institute (IRRI), Manila, Philippines. The diploid hybrid CW008 (AB, $2 n=2 x=24)$ of Sgdts96 $\times$ $O$. punctata and synthetic amphiploid DCW008 (AABB, $2 n=4 x=48$ ) were used in this study.

Crosses and chromosome doubling

The cultivar Sgdts96, HN2026 and Nipponbare were used as the female parents in crosses with $O$. punctata. In order to promote early flowering in wild rice, $O$. punctata was dark treated, using a short photoperiod of $8 \mathrm{~h}$ per day, for 30 days from 10 June to 9 July 2004 in Wuhan, China. After pollination, hormone treatment with 2, 4-D (10-30 $\mathrm{mg} \mathrm{l}^{-1}$ ) and $\mathrm{GA}_{3}\left(50-100 \mathrm{mg} \mathrm{l}^{-1}\right.$ ) was necessary. The immature hybrid embryos were excised and cultured on N6 solid medium

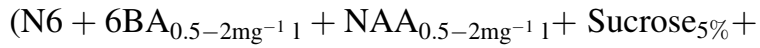
Agar $_{0.75 \%}$ ). For approximately 3 weeks, the shoots were transferred to a liquid medium with colchicine (500-750 $\mathrm{mg}^{-1} \mathrm{l}$ ) for chromosome doubling. 2 days later, they were shifted back to N6 medium. The shoots were rooted on $1 / 2$ MS medium with $0.5 \mathrm{mg}^{-1} 1 \mathrm{BA}$ and $0.3 \mathrm{mg}^{-1} 1 \mathrm{NAA}$. Plantlets with roots were transferred to the field.

Cytological observation and genomic in situ hybridization (GISH)

Root tips from $F_{1}$ and doubled plantlets were used for determination of the chromosome numbers. Directly-fixed flower buds were used for meiotic behavior observation (Li et al. 1995). Pollen fertility was determined as the percentage of pollen grains stained with $1 \% \mathrm{I}_{2}-\mathrm{KI}$.

For GISH, root tip cells were digested at $28{ }^{\circ} \mathrm{C}$ for about $4 \mathrm{~h}$ in an enzyme mixture containing $2 \%$ cellulase and $2 \%$ pectinase. Chromosome preparation mainly followed the method described by Yan et al. (1998) with some modifications. Total genomic DNA 
of $O$. sativa Sgdts96 and O. punctata was extracted from young leaves using CTAB. The DNA of O. punctata was fluorescently labeled with bio-11-dUTP using nick translation, according to the manufacturer's instructions (Sino-American Biotechnology Company), and used as the probe. The genomic DNA from Sgdts96 was sheared by autoclaving for $5 \mathrm{~min}$ and used as the block. In situ hybridization was carried out according to the method of Leitch et al. (1990).

\section{Comparison of morphology}

The main morphological traits of diploid and amphiploid hybrids were compared. Recording methods and standards were set according to the protocols of Gai (1996).

\section{Results}

The construction of diploid and amphiploid intergenomic hybrids

There was a very low success rate for natural hybridization between cultivated rice and wild rice.
The key to success for the wide cross is to overcome the problem of non-synchronization of flowering and cross-incompatibility. Currently, a short-day treatment was used to overcome the first problem. Principally it harmonizes flowering time between $O$. sativa and $O$. punctata at the same time. Then, hormone treatment and a combination of embryo rescue were used. Finally, intergenomic hybrids of Oryza sati$v a \times$ O. punctata were obtained (Fig. 1). Statistical data for the fertility of different cross combinations are listed in Table 1.

The hybrid shoots were cultured on the medium with $500-750 \mathrm{mg}^{-1} 1$ colchicine for chromosome doubling. The total number of synthetic amphiploid plants which were cytological confirmed was 10. And the doubling frequency was 9.09-14.81\% (Table 2). Root tip cells' mitotic metaphase from the doubled plants with $2 n=48$ revealed the success of chromosome doubling.

\section{Cytological and GISH analyses}

The chromosome numbers in root tips of diploid and amphiploid plants were counted. As expected,
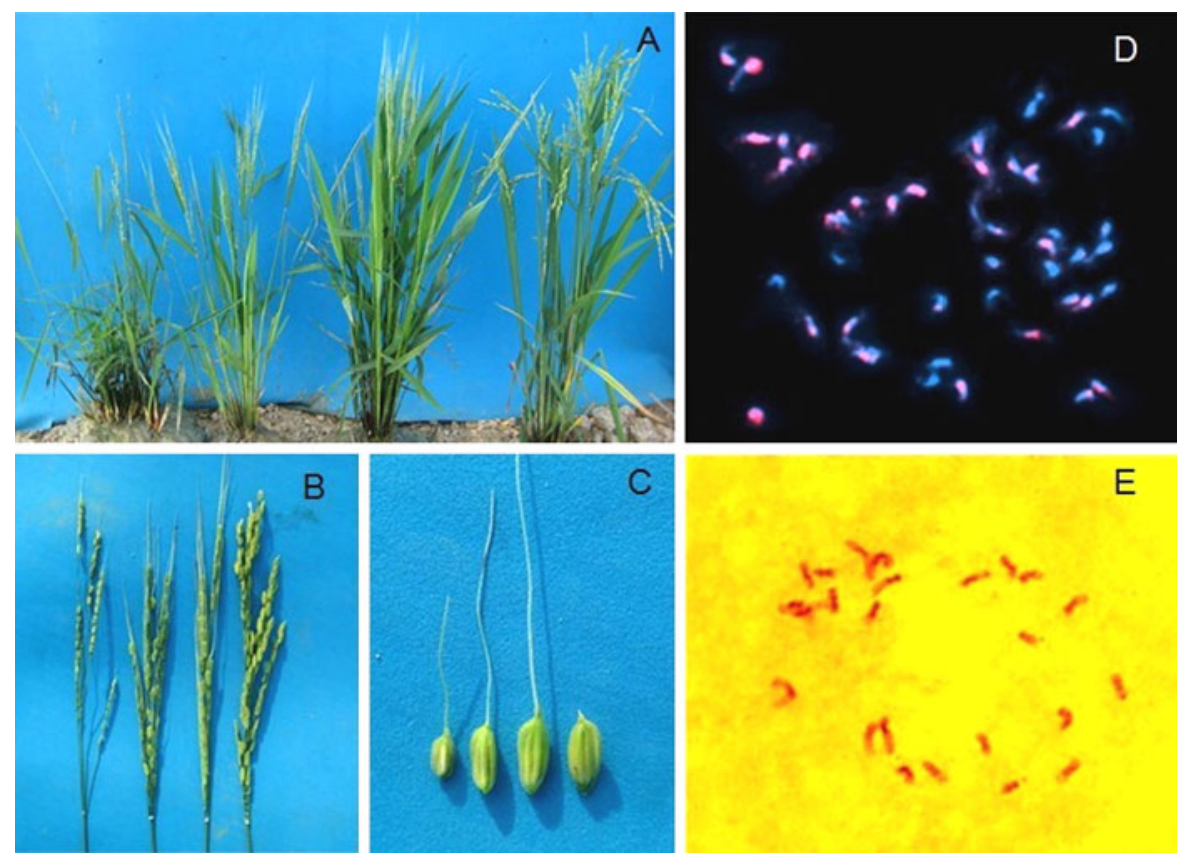

Fig. $1 O$. sativa, O. punctata and their hybrids. a plants $($ left $\rightarrow$ right): O. punctata (male parent); diploid hybrid; amphiploid hybrid; O. sativa Sgdts96 (female parent); b panicles $($ left $\rightarrow$ right $):$ O. punctata; diploid hybrid; amphiploid hybrid; O. sativa Sgdts96; c grains (left $\rightarrow$ right): O. punctata; diploid hybrid; amphiploid hybrid $O$. sativa Sgdts96; d GISH detection of amphiploid hybrid DCW008 (AABB, $2 n=4 x=48)$; e Chromosomes of intergenomic hybrid CW008 (AB, $2 n=2 x=24)$ 
Table 1 The fertility of interspecific crosses between $O$. sativa $\times O$. punctata

\begin{tabular}{lllllllr}
\hline $\begin{array}{l}\text { Hybrid } \\
\text { combination }\end{array}$ & Genome & $\begin{array}{l}\text { No. Of spikelets } \\
\text { pollinated }\end{array}$ & $\begin{array}{l}\text { No. of } \\
\text { seeds }\end{array}$ & $\begin{array}{l}\text { Seed } \\
\text { set }(\%)\end{array}$ & $\begin{array}{l}\text { No. of embryos } \\
\text { cultured }\end{array}$ & $\begin{array}{l}\text { No. of embryo } \\
\text { germination }\end{array}$ & $\begin{array}{l}\text { Percentage embryo } \\
\text { germination }(\%)\end{array}$ \\
\hline Sgdts96 $\times$ O. punctata & AB & 106 & 11 & 10.38 & 11 & 1 & 9.09 \\
HN2026 $\times$ O. punctata & AB & 508 & 19 & 3.74 & 19 & 4 & 21.05 \\
Nipponbare $\times$ O. punctata & AB & 219 & 13 & 5.94 & 13 & 3 & 23.08 \\
\hline
\end{tabular}

Table 2 Results of chromosome doubling

\begin{tabular}{lllll}
\hline $\begin{array}{l}\text { Hybrid } \\
\text { combination }\end{array}$ & $\begin{array}{l}\text { No. of } \\
\text { treated } \\
\text { shoots } \\
\text { (D) }\end{array}$ & $\begin{array}{l}\text { No. of } \\
\text { regenerated } \\
\text { plants }\end{array}$ & $\begin{array}{l}\text { No. of } \\
\text { tetraploid } \\
(\mathrm{T})\end{array}$ & $\begin{array}{l}\mathrm{T} / \mathrm{D} \\
\%\end{array}$ \\
\hline $\begin{array}{c}\text { Sgdts96 } \times \\
\text { O. punctata }\end{array}$ & 27 & 24 & 4 & 14.81 \\
$\begin{array}{c}\text { HN2026 } \times \\
\text { O. punctata }\end{array}$ & 29 & 21 & 3 & 10.34 \\
$\begin{array}{c}\text { Nipponbare } \times \\
\text { O. punctata }\end{array}$ & 33 & 30 & 3 & 9.09 \\
\hline
\end{tabular}

chromosomes of the intergenomic hybrid CW008 were $2 n=2 x=24$, and the synthetic amphiploid DCW008 were $2 n=4 x=48$ (Fig. 1d, e).

GISH investigations were performed on DCW008. GISH analyses indicated that 16 chromosomes were wholly labeled by the O. punctata probe. The other 11 chromosomes were partly labeled. We further investigated those partly labelled chromosomes. One arm was labeled on 2 chromosomes. And the chromosomal fragment attached to the terminal parts of 4 chromosomes. The other chromosomes' labeled fragments were irregular (Fig. 1d).

Pollen fertility test results

Pollen was stained by $\mathrm{I}_{2}-\mathrm{KI}$. The mature and normal pollen grains were full, round and dark. The aborted pollen grains could not be stained. Generally, the abortive pollen grains were irregular-shaped (small or triangular), and some had a round shape but no contents (Fig. 2). The staining rate of $F_{1}$ plants from the cross of $O$. sativa and $O$. punctata was nearly $0 \%$, while the staining rate of the amphidiploid was as high as $62.86 \%$.

Meiotic behavior of diploid and amphiploid hybrids

The diploid $F_{1}$ hybrids generally showed irregular meiosis, with mostly univalents. Of the 93 pollen mother cells (PMCs) observed, 58.51\% had more than 12 I and there was no quadrivalent (Table 3). The meiotic prophase I of the most PMCs from amphiploid hybrid had more than $18 \mathrm{II}$ and sometimes up to $24 \mathrm{II}$. Of the 99 PMCs, $57.58 \%$ showed 22-24 II. 2-3 quadrivalents association was recorded in $31.31 \%$ of the cells. Univalent hasn't been observed in amphiploid hybrid.

Through the observation of meiotic metaphase I and anaphase I of the PMCs, we found that the percentage of lagging chromosomes in the diploid hybrid's PMCs reached $34.90 \%$. The ratio with three or more lagging chromosomes of PMCs was $6.93 \%$ (Table 4). However, more than $92.71 \%$ of the PMCs in the synthetic amphiploid DCW008 were normal. The percentage of cells seen with lagging chromosomes was only $7.29 \%$ of the total number of PMCs. Generally, there was only one lagging chromosome. Two lagging chromosomes only appeared in $1.04 \%$ of the PMCs. The result further demonstrated that meiosis had a great impact on fertility. Pollen mother cells from the diploid hybrid had a small number of bivalents and chromosome pairing disorders. In meiotic anaphase I, there appeared a large number of lagging chromosomes (Fig. 3b-c). They could not form normal gametes, which led to a high degree of infertility. By chromosome doubling, each chromosome paired up with another homologous chromosome, which normalized meiosis (Fig. 3d-e), thereby increasing fertility.

Agronomic traits of diploid and amphiploid hybrids

Compared to the $O$. punctata parent, the hybrids overcame many wild traits except the shattering and awn traits. The synthetic amphiploid plants had more sturdy stems and larger leaves and grains. In addition, the amphiploid plants showed stronger growth and tillering (Fig. $4 \mathrm{a}-\mathrm{c}$ ). The main agronomic traits 

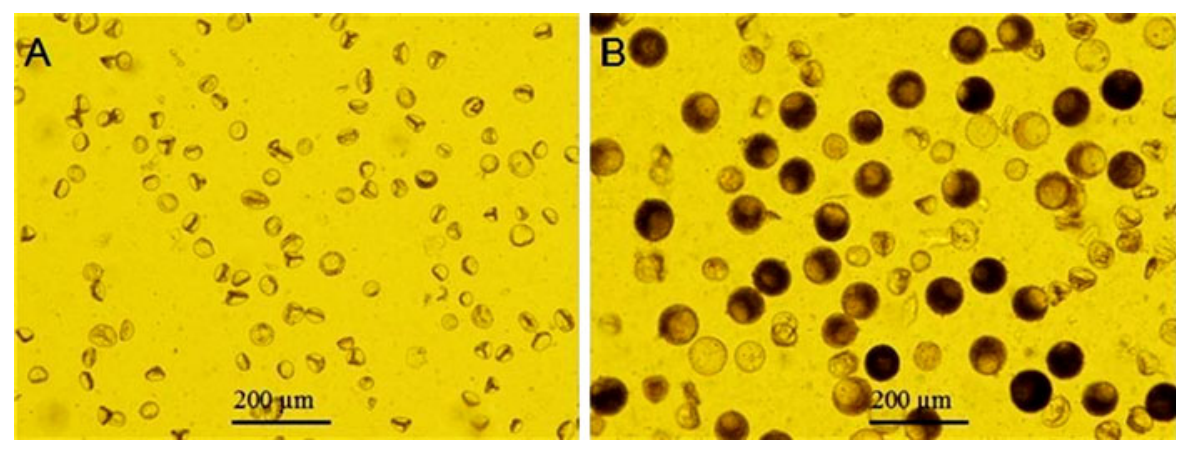

Fig. 2 Pollen staining pictures of diploid hybrid and amphiploid. a Abortive pollen from diploid hybrid CW008, b many stained pollen grains from amphiploid DCW008

Table 3 Observations of meiotic prophase I of the intergenomic diploid and amphiploid hybrids

\begin{tabular}{|c|c|c|c|c|c|c|c|c|}
\hline \multirow[t]{2}{*}{ Hybrid } & \multirow[t]{2}{*}{ Number of PMCs } & \multicolumn{2}{|c|}{ Univalent/cell (no.) (no.) } & \multicolumn{2}{|c|}{ Bivalent/cell (no.) } & \multicolumn{2}{|c|}{ Quadrivalent/cell (no.) } & \multirow[t]{2}{*}{ Percentage $(\%)$} \\
\hline & & Mean & Range & Mean & Range & Mean & Range & \\
\hline \multirow[t]{4}{*}{ CW008 (2x) } & 19 & 19.26 & $18-22$ & 2.37 & $1-3$ & I & / & 20.21 \\
\hline & 36 & 14.22 & $12-16$ & 4.89 & $4-6$ & I & I & 38.30 \\
\hline & 33 & 8.18 & $6-10$ & 8.52 & $7-9$ & / & I & 35.12 \\
\hline & 5 & 3.60 & $10-11$ & 10.20 & $2-4$ & l & l & 5.32 \\
\hline \multirow[t]{3}{*}{ DCW008 (4x) } & 57 & / & / & 22.37 & $22-24$ & 0.82 & $0-1$ & 57.58 \\
\hline & 31 & / & I & 19.42 & $18-20$ & 2.29 & $2-3$ & 31.31 \\
\hline & 11 & Others & & & & & & 11.11 \\
\hline
\end{tabular}

I univalent, II bivalent, IV quadrivalent

Table 4 Lagging chromosomes of the meiotic metaphase I and anaphase I of diploid and tetraploid hybrids

\begin{tabular}{llll}
\hline Hybrid & $\begin{array}{l}\text { Lagging } \\
\text { chromosomes }\end{array}$ & $\begin{array}{l}\text { Number of } \\
\text { PMCs }\end{array}$ & $\begin{array}{l}\text { Percentage } \\
(\%)\end{array}$ \\
\hline CW008 (2x) & 0 & 47 & 66.10 \\
& 1 & 10 & 13.89 \\
& 2 & 10 & 14.08 \\
DCW008 (4x) & 0 & 5 & 6.93 \\
& 1 & 89 & 92.71 \\
& 2 & 6 & 6.25 \\
& 2 & 1 & 1.04 \\
\hline
\end{tabular}

showed no obvious character segregations in $F_{1}-F_{3}$ generations, which were relatively uniform (Fig. 4d-f). The diploid hybrids were completely infertile but amphiploid plants had good seed set after selfing, with some variations in seed setting (31.52-37.65\%) (Table 5). After several years' selection, the seed setting rate of some intergenomic amphiploid hybrid plant lines can reach about $60 \%$.

\section{Discussion}

Gene introgression from wild rice

Wild rice has many useful genes for traits, which involve the function of insect resistance, disease resistance, stress tolerance, high yield and high grain quality. Gene introgression is generally used to transfer useful genes from wild species into rice. Many genes from wild species have been transferred into cultivated rice through the introgression method. But gene introgression in diploid level has limitations. First, in the genus Oryza, interspecific hybridization is normally characterized by low seed set (0-26.5\%) that is commonly less than $10 \%$ (Sitch et al. 1989a). And especially when involving intergenomic crosses, the hybrids are completely sterile. In this study, crosses between three varieties of $O$. sativa as the female parents and $O$. punctata as male parent gave seed sets between 3.74 and $10.38 \%$. Second, the diploid $F_{1}$ hybrids are usually completely sterile. In 


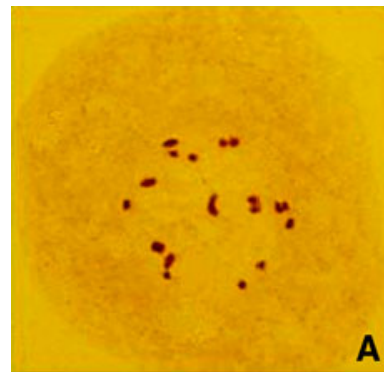

A

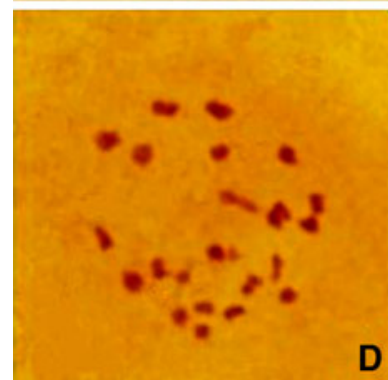

D

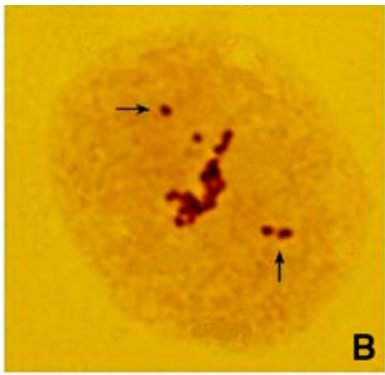

B

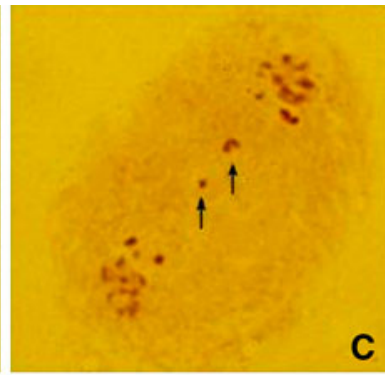

E

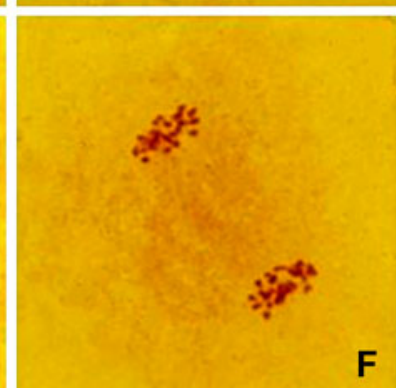

Fig. 3 Meiosis I of diploid and amphidiploid intergenomic hybrids of $O$. sativa $\times O$. punctata. a-c Meiosis I of diploid hybrid (a prophase I, $\mathbf{b}$ metaphase I, $\mathbf{c}$ anaphase I), d-f meiosis I of amphiploid hybrid (d prophase I, e metaphase I, f anaphase I) (The arrows indicate the lagging chromosomes)

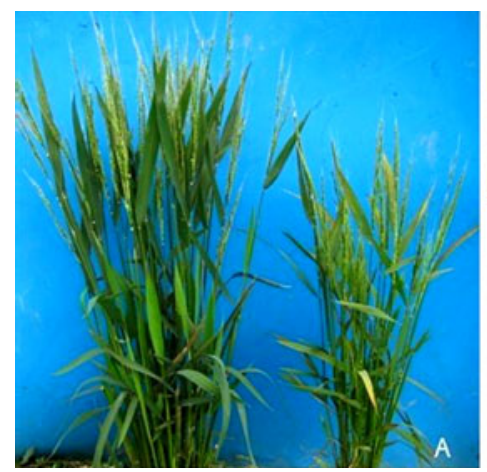

Fig. 4 Morphology of diploid and amphiploid hybrids. a Plants (left amphiploid, DCW008; right diploid, CW008), b grains (left diploid, CW008; right amphiploid, DCW008), c panicles (left

this investigation, pollen fertility of diploid $\mathrm{F}_{1}$ hybrids of $O$. sativa and $O$. punctata was $0 \%$. There were also non-functional female gametes produced by diploid $F_{1}$ hybrids. Mariam et al. (1996) approved that the sterility could be due to differences in the structure and number of chromosomes, a lack of chromosomal homology that results in a variable number of univalents and the production of unbalanced gametes that leads to high pollen abortion. Multani et al. (2003) reported that crossability of the $\mathrm{F}_{1}$ hybrids of $O$. sativa and wild rice was extremely low and no seeds were obtained upon backcrossing.
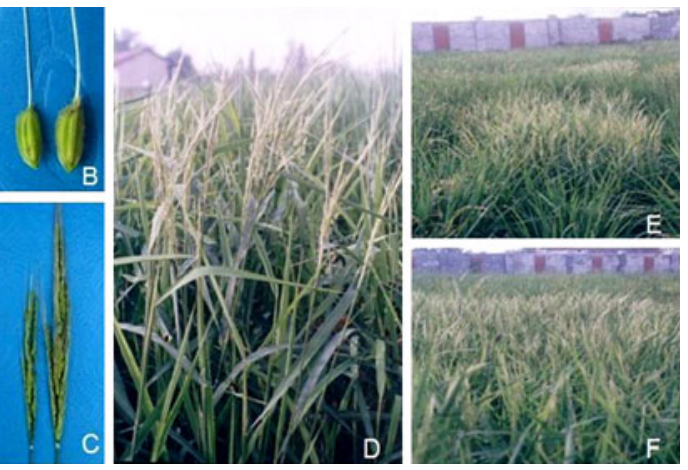

diploid, CW008; right amphiploid, DCW008), d DCW008 $\mathrm{F}_{1}$, e DCW008 $\mathrm{F}_{2}$, f DCW008 $\mathrm{F}_{3}$

However, when interspecific diploid hybrids doubled into allopolyploid by colchicine, their fertility can be partly restored. They can produce functional female gametes and have good seed set after selfing. As shown in this study, synthetic allopolyploid DCW008 was fertile. There are many allopolyploid wild rice species in nature, such as O. minuta (BBCC), O. malampuzhaensis (BBCC), O. alta (CCDD), O. grandiglumic (CCDD), O. latifolia (CCDD), O. longiglumis (HHJJ), O. ridleyi (HHJJ) and O. schlechteri (HHKK) (Qian and Chen 2006). So, establishing gene introgression through allopolyploid as a bridge role can 
Table 5 Agronomic traits of diploid and amphiploid plants

\begin{tabular}{|c|c|c|c|c|c|c|c|c|c|}
\hline \multirow{2}{*}{$\begin{array}{l}\text { Line or } \\
\text { hybrid }\end{array}$} & \multirow{2}{*}{$\begin{array}{l}\text { Plant } \\
\text { height }(\mathrm{cm})\end{array}$} & \multirow{2}{*}{$\begin{array}{l}\text { Spike } \\
\text { length }(\mathrm{cm})\end{array}$} & \multirow{2}{*}{$\begin{array}{l}\text { Grain length/ } \\
\text { width }(\mathrm{cm})\end{array}$} & \multirow{2}{*}{$\begin{array}{l}\text { Awn } \\
\text { length } \\
(\mathrm{cm})\end{array}$} & \multicolumn{2}{|c|}{ Flag leave angle } & \multirow{2}{*}{$\begin{array}{l}\text { Leaf area } \\
\left(\mathrm{cm}^{2}\right)\end{array}$} & \multirow{2}{*}{$\begin{array}{l}\text { Seed set } \\
(\%)\end{array}$} & \multirow{2}{*}{$\begin{array}{l}\text { Shattering } \\
\text { trait }\end{array}$} \\
\hline & & & & & $\leq 30^{\circ}$ & $>30^{\circ}$ & & & \\
\hline Sgdts96-2x & 62.70 & 16.73 & $0.68 / 0.25$ & $0-0.04$ & $100 \%$ & 0 & 33.14 & 88.14 & Difficult \\
\hline HN2026-2x & 61.63 & 20.90 & $0.70 / 0.32$ & $0-0.60$ & $100 \%$ & 0 & 65.92 & 85.71 & Difficult \\
\hline $\begin{array}{l}\text { Nipponbare- } \\
2 \mathrm{x}\end{array}$ & 79.30 & 20.70 & $0.65 / 0.34$ & 0 & $100 \%$ & 0 & 32.67 & 81.30 & Difficult \\
\hline $\begin{array}{l}\text { O. punctata- } \\
2 \mathrm{x}\end{array}$ & 55.87 & 15.94 & $0.65 / 0.25$ & $2.10-5.5$ & $4.63 \%$ & $95.47 \%$ & 15.64 & 12.32 & Easy \\
\hline CW008-2x & 85.28 & 8.89 & $0.53 / 0.25$ & $0.22-2.81$ & $14.29 \%$ & $85.71 \%$ & 15.26 & 0 & Easy \\
\hline $\begin{array}{l}\text { DCW008- } \\
4 \mathrm{x} \mathrm{F}_{1}\end{array}$ & 114.80 & 18.31 & $0.84 / 0.29$ & $0.10-4.72$ & $55.93 \%$ & $44.07 \%$ & 20.07 & 31.52 & Easy \\
\hline $\begin{array}{l}\text { DCW008- } \\
4 \mathrm{xF}_{2}\end{array}$ & 115.21 & 20.90 & $0.82 / 0.31$ & $0.34-5.10$ & $50.12 \%$ & $49.88 \%$ & 26.21 & 37.65 & Easy \\
\hline $\begin{array}{l}\text { DCW008- } \\
4 \mathrm{x} \mathrm{F}_{3}\end{array}$ & 115.82 & 18.74 & $0.81 / 0.33$ & $0.31-4.50$ & $53.64 \%$ & $46.36 \%$ & 25.37 & 35.65 & Easy \\
\hline
\end{tabular}

improve efficiency to transfer useful genes from the wild species. In the present study, chromosome fragment introgression and chromosome recombination could be observed through GISH investigations which were performed on synthetic amphiploid DCW008 (Fig. 1d). Multani et al. (1994) produced a triploid hybrid by crossing an artificial tetraploid of $O$. sativa and normal diploid $O$. australiensis and developed monosomic alien addition lines and gene introgression. Mariam et al. (1996) doubled interspecific hybrid $F_{1}$ and backcrossed with cultivated rice. Finally, they obtained bacterial blight resistance from O. minuta.

Allopolyploid play an important role in breeding programs and the.genetic and evolutionary studies of wheat (Goncharov et al. 2007), cotton (Flagel et al. 2008), rape (Albertin et al. 2006) and so on. From an evolutionary point of view, a different genomic combination and polyploidization reflect the general direction of the evolution of crops (Cai et al. 2001). Synthetic allopolyploid rice will probably produce new polyploid germplasm resources just as wheat, cotton, rape and groundnut once did.

Homoeology of the A and B genome

There are many studies involved relationship between $\mathrm{A}$ and $\mathrm{B}$ genome, usually amongst A, B and C. Qiu et al. (2010) considered that B and $C$ genomes had genetic relationship with $\mathrm{A}$ which was the basic genome. Through the phylogenetic tree of the genus Oryza, genetic relationship between A and B is closer than A and C (Nishikawa et al. 2005). Gao et al. (2007) had the same viewpoint. In this investigation, meiotic chromosome pairing in diploid $\mathrm{F}_{1}$ hybrids of $O$. sativa and O. punctata was irregular, with mostly univalents. But $73.42 \%$ of the pollen mother cells (PMCs) had means $4.89-8.52$ bivalents. The meiotic prophase I of the PMCs from the $31.31 \%$ synthetic amphiploid hybrids had means 2.29 quadrivalents. $11.11 \%$ of PMCs had more than four quadrivalents. Based on the pairing in interspecific diploid and amphiploid hybrids, it can be considered due to homoeologous pairings of chromosomes among $\mathrm{A}$ and $\mathrm{B}$ genomes. So, the occurrence of bivalents in diploid and quadrivalents in amphiploid could be attributed to allosyndesis. It indicated that the $\mathrm{A}$ and $\mathrm{B}$ genomes were partial homology, which is beneficial to transfer some useful genes from wild rice to cultivated rice.

Acknowledgments The study was supported by the National Natural Science Foundation of China (Grant No. 31271690, 31270356, 31140033, 30971751), the National 'Twelfth FiveYear' Support Plan for Science \& Technology of China (Grant No. 2011BAD35B02). We are grateful to the anonymous reviewers for their constructive comments on revision of the manuscript.

Open Access This article is distributed under the terms of the Creative Commons Attribution License which permits any use, distribution, and reproduction in any medium, provided the original author(s) and the source are credited. 


\section{References}

Albertin W, Balliau T, Brabant P et al (2006) Numerous and rapid nonstochastic modifications of gene products in newly synthesized Brassica napus allotetraploids. Genetics 173:1101-1113

Amante-Bordeos A, Sitch LA, Nelson R et al (1992) Transfer of bacterial blight and blast resistance from the tetraploid wild rice Oryza minuta to cultivated rice, Oryza sativa. Theor Appl Genet 84:345-354

Cai DT, Yuan LP, Lu XG (2001) A new strategy of rice breeding in the 21st century. Searching a new pathway of rice breeding by utilization of double heterosis of wide cross and polyploidization. Acta Agronomica Sinica. 27(1):110-116

Carvalho A, Guedes-Pinto H, Mártín A, Heslop-Harrison P, Lima-Brito J (2005) Genome discrimination and chromosome pairing in the Hordeum chilense $\times$ Aegilops tauschii amphiploid. Euphytica 144:85-89

Deng HB, Deng QY, Chen LY (2006) Researches and utilization on wild rice resources. China Agric Sci Bull 22(1):295-299

Flagel L, Udall J, Nettleton D, Wendel J (2008) Duplicate gene expression in allopolyploid Gossypium reveals two temporally distinct phases of expression evolution. BMC Biol $6: 16$

Gai JY (1996) Crop breeding (special). China Agriculture Press, Beijing, pp 43-45

Gao L, Wang DB, Liu XQ, Qin R (2007) Compar ative analysis of genomes in Oryza Sativa, O. punctata and O. Officinalis (in Chinese). Hubei Agric Sci 46(4):491-494

Goncharov NP, Bannikova SV, Kawahara T (2007) Wheat artificial amphiploids involving the Triticum timopheevii genome: their studies, preservation and reproduction. Genet Resour Crop Evol 54:1507-1516

He GC (1998) Cellular and molecular approaches in exploitation of useful genes in wild rice. Prog Biotechnol 18(2):41-45

Huang QC, Sun MY, Deng QY (2001) Polyploid rice and its potential value (in Chinese). Hybrid Rice 16(1)

Khush GS (1977) Disease and insect resistance in rice. Adv Agron 29:265-341

Khush GS, Bacalangco E, Ogawa T (1990) A new gene for resistance to bacterial blight from $O$. longistaminata. Rice Genet Newslett 7:121-122

Leitch AR, Mosgoller W, Schwarzacher T, Bennett MD, Heslop-Harrison JS (1990) Genomic in situ hybridization to sectioned nuclei shows chromosome domains in grass hybrids [J]. Cell Sci 95:335-341
Li Z, Liu HL, Luo P (1995) Production and cytogenetics of intergeneric hybrids between Brassica napus and Orychophragmus violaceus. Theor Appl Genet 91:131-136

Lin SC, Yuan LP (1980) Hybrid rice breeding in China. Innovative approaches to rice breeding. International Rice Research Institute, Manila, pp 35-51

Mariam AL, Zakri AH, Mahani MC (1996) Interspecific hybridization of cultivated rice, Oryza sativa L. with the wild rice, O. minuta. Pres1. Theor Appl Genet 93:664-671

Multani DS, Jena KK, Brar DS, Reyes BG, Angeles ER, Khush GS (1994) Development of monosomic alien addition lines and introgression of genes from Oryza australiensis Domin. to cultivated rice $O$. sativa $\mathrm{L}$. Theor Appl Genet 88:102-109

Multani DS, Khush GS, delos Reyes BG, Brar DS (2003) Alien genes introgression and development of monosomic alien addition lines from Oryza latifolia Desv. to rice Oryza sativa L. Theor Appl Genet 107:395-405

Nishikawa T, Vaughan DA, Kadowaki K (2005) Phylogenetic analysis species, based on simple sequence repeats and their flanking nucleotide sequences from the mitochondrial and chloroplast genomes[J]. Theor Appl Genet 110:696-705

Qian Q, Chen SH (2006) Rice genetics and functional genomics. Science Press, Beijing

Qiu XF, Liu H, Qin R, Chen Y (2010) Fluorescence in situ hybridization of Oryza schweinfurthian chromosomes with genomic DNA from $O$. sativa (in chinese). J Huazhong Agric Univ 29:537-540

Sitch LA, Dalmacio RD, Romero GO (1989a) Crossability of the wild Oryza species and their potential use for improvement of cultivated rice (Oryza sativa L.) Rice Genet Newslett 6: 58-60

Wang AY, Chen DL, Cai DT (2005) Applications of wide hybridization and allopolyploidization in rice breeding. J Wuhan Bot Res 23(5):491-495

Yan HM, Song YC, Li LJ et al (1998) Physical location of rice $P i-5(t), G l h$ and RTSV genens by ISH of BAC clones. Wuhan Univ J Nat Sci 3:226-230

Zhong DB, Luo LJ, Ying CS (2000) Advances on transferring elite gene from wild rice species into cultivated rice (in Chinese). Chin J Rice Sci 14:103-106

Zhu JF, Liu YQ, Wang AY et al (2008) The cellular and embryologic studies on allohexaploid rice AACCDD and triploid rice ACD. J Plant Genet Resour 9(3):350-357 